\title{
Greenhouse gas emissions from Irish beef and dairy production systems
}

P. Crosson ${ }^{1}$, P.A. Foley ${ }^{4}$, L. Shalloo ${ }^{2}$, D. O'Brien ${ }^{2,4}$, D.A. Kenny ${ }^{3}$

${ }^{1}$ Teagasc, Grange Beef Research Centre, Dunsany, Co. Meath, Ireland, ${ }^{2}$ Teagasc, Moorepark Dairy Production Research Centre, Fermoy, Co. Cork, Ireland, ${ }^{3}$ Teagasc, Animal Bioscience Centre, Dunsany, Co. Meath, Ireland, ${ }^{4}$ University College Dublin, School of Agriculture, Food Science and Veterinary Medicine, Belfield, Dublin 4, Ireland

Email:paul.crosson@teagasc.ie

Introduction In Ireland, agriculturally derived emissions account for $26 \%$ of total greenhouse gas emissions (McGettigan et al., 2009). Emissions from agriculture reduced by 7\% in 2007 relative to 1990 levels with a further 4\% reduction projected by 2020 (McGettigan et al., 2009). These projections relate to the levels of agricultural activity and thus, there is scope to reduce emissions further if production efficiency at farm level is also improved. Furthermore, new technologies that directly reduce the emissions of methane $\left(\mathrm{CH}_{4}\right)$ or nitrous oxide $\left(\mathrm{N}_{2} \mathrm{O}\right)$ will, if adopted on farms, reduce the contribution from agriculture even further again (Beauchemin et al., 2008; de Klein and Eckard, 2008). Systems modelling approaches have been used to investigate the GHG emissions from current and prototype agricultural production systems (Schils et al., 2007). This paper reports on a number of studies which have attempted to quantify GHG emissions from Irish beef and dairy production systems.

Modelling approaches Whole-farm systems modelling determines the GHG emissions association with agricultural products by integrating the farm production profile with the relevant GHG conversion factors and converting the computed emissions to their global warming potential carbon dioxide $\left(\mathrm{CO}_{2}\right)$ equivalent. Emissions from Irish livestock production systems have been investigated in this way (Foley, 2009; Foley et al., 2010; Lovett et al., 2006; O'Brien et al., 2010). Foley (2009) and Foley et al. (2010) modelled GHG emissions per unit area and per unit product for suckler-beef and dairy-beef production systems. Input data was generated using a bioeconomic model of beef production systems thus permitting concomitant financial analysis (Crosson, 2008). A range of scenarios representing average Irish farm systems as well as incorporating data from research production systems differing in production intensity were investigated. O Brien $e t$ al. (2010) linked a GHG model to a bioeconomic dairy systems model (Shalloo et al., 2004) to evaluate GHG emissions and technical and financial performance of dairy production systems. This model has been used to investigate the effect of cow genotype, feed system, grazing season length and overall herd breeding index on dairy production GHG emissions per unit of product and per unit area.

Findings Foley et al. (2010) found that, for suckler beef production systems, emissions per farm and per unit area were substantially higher for research systems relative to average Irish farm systems due to higher stocking rates. However, per $\mathrm{kg}$ beef carcass, reductions in GHG emissions were in the order of $20 \%$ for research production systems. The main drivers of this reduction were level of beef carcass output, level of animal performance, efficiency of grass utilisation and efficiency of fertiliser utilisation (Foley et al., 2010). Similarly, for dairy-beef production systems, emissions were approximately 30\% lower for research production systems relative to average Irish farm systems (Foley, 2009). For both suckler and dairy beef production systems, reduced emissions per kg product were associated with higher levels of profitability.

In the case of dairy production systems, O'Brien et al. (2010) found that low concentrate systems and selecting cows based on both production and fertility traits produced the lowest GHG emissions per $\mathrm{kg}$ of milk solids. These results agree with the findings of Lovett et al. (2006) who also showed that cows selected solely for increased milk production potential increase GHG emissions per unit of product. Furthermore, the results of these studies (Lovett et al., 2006; O'Brien et al., 2010) indicated that profit can be increased and emissions per unit of product decreased by adopting available technologies. Thus, there is large potential to reduce the national average GHG emission for dairy production systems per unit of product without eroding farm profitability. The main technologies available to decrease national dairy emissions are improved fertility, early calving date, increased grazing season length, higher stocking rates and improved milk composition and yield.

\section{References}

Beauchemin, K.A., Kreuzer, M., O’Mara, F.P. and McAllister, T.A. 2008. Australian Journal of Experimental Agriculture 48, 21-27

Crosson, P. 2008. Proceedings of the $22^{\text {nd }}$ meeting of the European Grassland Federation, 771.

de Klein, C.A.M and Eckard, R.J. 2008. Australian Journal of Experimental Agriculture 48, 14-20.

Foley, P.A., Crosson, P., Lovett, D.K., Boland, T.M., O’Mara, F.P. and Kenny, D.A. 2010. Agriculture, Ecosystems and the Environment (In review).

Foley, P.A. 2009. Ph.D. thesis, University College Dublin.

Lovett, D. K., Shalloo, L, Dillon, P. and O’Mara, F.P. 2006. Agricultural Systems 88(2-3), 156-179.

McGettigan, M., Duffy, P., Hyde, B., Hanley, E. and O’Brien, P. 2009. National Inventory Report 2009, EPA.

O’Brien, D., Shalloo, L., Grainger, C., Buckley, F., Horan, B., and Wallace, M. 2010. Journal of Dairy Science (In review)

Schils, R. L. M., Olesen, J.E., del Prado, A. and Soussanna, J.F. 2007. Livestock Science 112(3), $240-251$.

Shalloo, L., Dillon, P., Rath, M. and Wallace, M. 2004. Journal of Dairy Science 87, 1945-1959. 